\title{
Clinical and Radiological Results with Second-Look Arthroscopic Findings after Open Wedge High Tibial Osteotomy without Arthroscopic Procedures for Medial Meniscal Root Tears
}

\author{
Hyun Il Lee, MD, Dongjun Park, MD, and Jinho Cho, MD, PhD \\ Department of Orthopedic Surgery, Inje University Ilsan Paik Hospital, Goyang, Korea
}

\begin{abstract}
Purpose: To identify the structural integrity of the healing site after medial open wedge high tibial osteotomy (MOWHTO) in patients with a posterior root tear of the medial meniscus (PRTMM) and chondral lesion by second-look arthroscopy and to determine the clinical and radiological findings.

Materials and Methods: From August 2010 to June 2016, 52 consecutive patients underwent MOWHTO and arthroscopic examination without a chondral resurfacing procedure and meniscal treatment for PRTMM. Twenty-four patients were available for second-look arthroscopic evaluation. The mean follow-up period was 19.5 months (range, 5 to 46 months). Clinical evaluation was based on the Lysholm knee scores and Hospital for Special Surgery (HSS) scores.

Results: There were 5 lax healing, 6 scar tissue, 13 failed healing of PRTMM. Definite change of chondral lesion was not observed. The KellgrenLawrence grade did not improve according to the follow-up plain radiograph. The mean Lysholm score improved from 34.7 preoperatively to 77.1 at the last follow-up, and the mean HSS score significantly increased from 36.5 to 82.4.

Conclusions: This study revealed a low rate of healing potency of PRTMM and chondral lesion after MOWHTO without any attempt for meniscal treatment or chondral resurfacing. The cartilage and healing status of PRTMM was not associated with improved clinical outcomes and radiological findings.
\end{abstract}

Keywords: Knee, Osteoarthritis, Medial meniscus, Root tear, Osteotomy, Open wedge

\section{Introduction}

The meniscus plays an important multifunctional role in maintaining the overall function of the knee, which involves load transmission, shock absorption, joint stability and lubrication, proprioception, and nutrient supply ${ }^{1,2)}$. Injuries involving detach-

Received June 4, 2017; Revised (1st) September 18, 2017;

(2nd) November 3, 2017; Accepted December 11, 2017

Correspondence to: Jinho Cho, MD, PhD

Department of Orthopedic Surgery, Inje University Ilsan Paik Hospital,

170 Juhwa-ro, Ilsanseo-gu, Goyang 10380, Korea

Tel: +82-31-910-7301, Fax: +82-31-910-7967

E-mail: osd07@paik.ac.kr

This is an Open Access article distributed under the terms of the Creative Commons Attribution Non-Commercial License (http://creativecommons.org/licenses/by-nc/4.0/) which permits unrestricted non-commercial use, distribution, and reproduction in any medium, provided the original work is properly cited. ment of the meniscus affect meniscal biomechanics and kinematics, leading to accelerated degenerative changes within the knee joint. In particular, posterior root tears of the medial meniscus (PRTMM) have recently become a recognized issue, as a root tear destroys the ability of the meniscus to withstand hoop tension. PRTMM is considered a radial tear or avulsion at the insertion of the medial meniscus, and it often may go unnoticed ${ }^{3}$. This pathology may cause medial meniscus extrusion, loss of articular cartilage, and joint space narrowing, and it eventually progresses to medial compartment degenerative osteoarthritis ${ }^{4-9}$. Hence, there has been an increasing interest in the surgical repair of tears at the meniscal root ${ }^{3,9,10-16)}$.

High tibial osteotomy (HTO) was originally devised to treat medial compartment osteoarthritis of the knee with varus deformity. Decreasing the pressure on the medial compartment by altering the weight-bearing axis may lead to remodeling of the 
articular cartilage ${ }^{17)}$. However, few articles have reported that regeneration of the articular cartilage is associated with clinical improvement. Furthermore, the specific factors influencing cartilage regeneration remain unclear.

A recent study showed that reducing contact stress using HTO can heal PRTMM ${ }^{18}$. Nha et al. ${ }^{19)}$ found that high tibial corrective osteotomy in patients with combined PRTMM and varus deformity resulted in acceptable clinical improvements in 20 patients. Furthermore, 10 of these patients showed complete repair during a second-look arthroscopic examination, while 6 showed incomplete repair. However, this study was unable to determine the exact healing mechanism of PRTMM.

The objectives of the present study were as follows: 1 ) to assess the structural integrity of the meniscal healing site and determine articular cartilage status using second-look arthroscopy; and 2) to evaluate the clinical relevance of these findings after medial open wedge high tibial osteotomy (MOWHTO).

\section{Materials and Methods}

\section{Patient Selection and Study Design}

This was a retrospective study approved by the institution's ethical review committee (Institutional Review Board No. ISPAIK 2016-09-004-001). Fifty-two MOWHTOs were performed. The study group comprised 52 patients ( 7 males and 45 females) with varus deformities who were surgically treated for medial compartment osteoarthritis or PRTMM. The procedures took place in our hospital from August 2010 to June 2016, and all procedures were performed by the same orthopedic surgeon. All the patients presented with pain on the medial side of the knee. Weight bearing anteroposterior radiographs were taken in each case, and all knees showed varus deformities with medial joint space narrowing. The progression of osteoarthritis was evaluated by using the Kellgren-Lawrence radiographic grading scale.

Among 52 consecutive patients, 24 underwent second-look arthroscopy, and they were enrolled in this study. Data were analyzed, including information obtained from reviewing medical records and arthroscopic findings. Second-look arthroscopy was performed in 23 patients following hardware removal upon the patient's request 1 year following surgery.

\section{Exclusion Criteria}

Patients with a history of injury, tibial fracture, chronic instability of the knee, infection of the knee, severe osteoarthritis of the patellofemoral joint, femorotibial angle (FTA) more than $185^{\circ}$ ( $5^{\circ}$ of anatomic varus), or flexion contracture more than $15^{\circ}$ were excluded from the study.

\section{Surgical Technique}

Preoperative planning included determination of the desired correction using full-length standing radiographs according to the method of Miniaci. The mechanical axis was shifted to a point $62 \%$ lateral on the transverse diameter of the tibial plateau according to the criteria of Fujisawa.

The procedure was performed under general or spinal anesthesia with the patients placed in a supine position on a radiolucent standard operating table a with lateral support. Initial knee arthroscopy was first performed on every patient to evaluate cartilage status and meniscal injury. The joint surface was not treated in any patient. An oblique incision $60 \mathrm{~mm}$ to $80 \mathrm{~mm}$ long, $40 \mathrm{~mm}$ distal to the joint line, and $10 \mathrm{~mm}$ proximal to the pes anserinus was made, extending from the medial aspect of the tibial tuberosity to the posterior border of the tibial plateau. The semitendinosus and gracilis tendons were cut at the point of tibial insertion; medial collateral ligaments were released from the posteromedial cortex of the tibia; and a Hohmann retractor was inserted to protect the neurovascular structures. The first oblique osteotomy was started at the upper margin of the pes anserinus (approximately $35 \mathrm{~mm}$ distal to the medial proximal tibial joint surface), and it ended $10 \mathrm{~mm}$ from the lateral cortical margin at the upper level of the proximal tibiofibular joint. The second frontal osteotomy was started $10 \mathrm{~mm}$ or more proximal to the insertion of the patellar tendon to the first osteotomy plane (biplanar osteotomy). These osteotomy procedures were performed with a micro bone saw and completed with the use of chisels. The osteotomy site was opened by insertion of a specially designed bone spreader at a distance determined by a goniometer under fluoroscopic control. Alignment was checked using the rod method. The tibial slope was not changed. A TomoFix plate (DePuy Synthes, West Chester, PA, USA) was inserted into a subcutaneous tunnel over the soft tissues on the anteromedial aspect of the tibia and fixed in place with 8 locking screws with minimal invasiveness. Artificial bone graft materials (B-tricalcium phosphate wedges [GeneX, Biocomposites Ltd., Staffordshire, UK] and ChronOS [DePuy Synthes]) were used to form a triangular pole equivalent to the size of the opening, and then it was inserted into the osteotomy site (Fig. 1).

\section{Radiological Evaluation}

Radiological evaluations of the mechanical FTA were performed using an anteroposterior weight-bearing radiograph taken with the knee joint in extension at 3 months and 1 year 

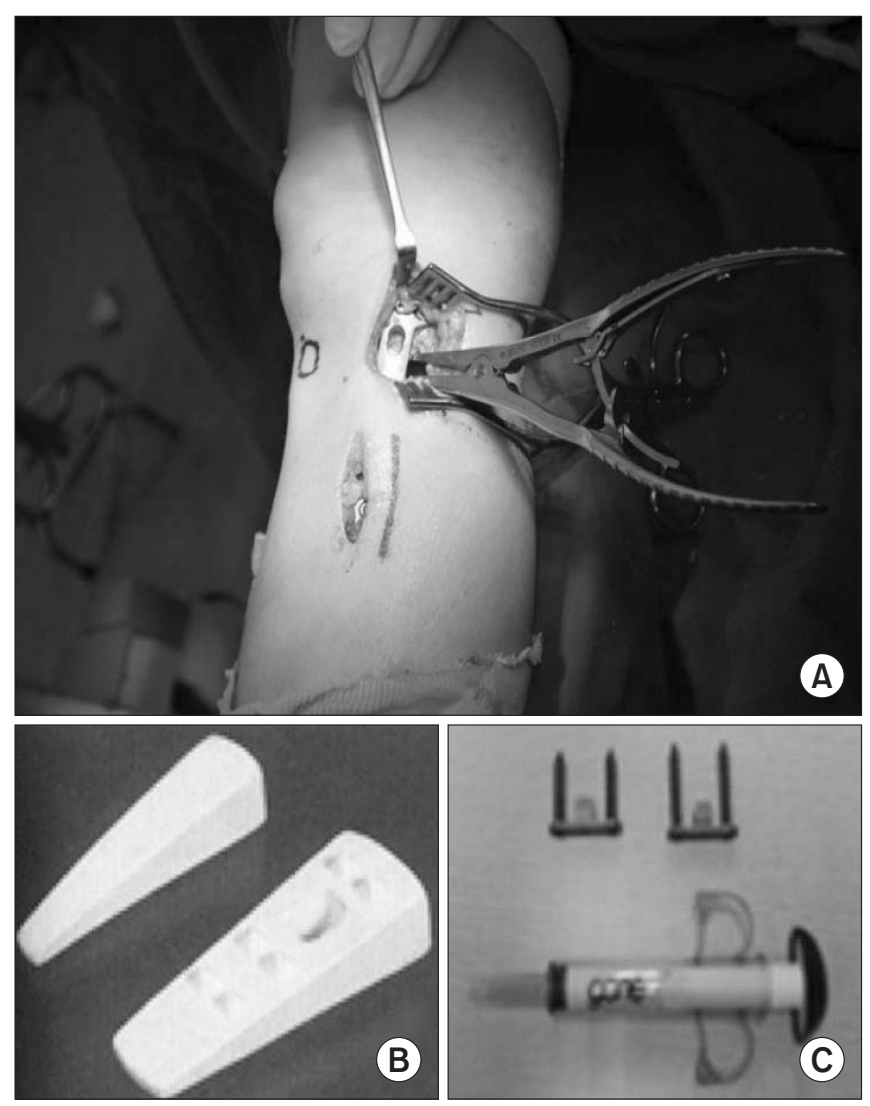

Fig. 1. Stabilization of open wedge in high tibial osteotomy. (A) After medial open wedge high tibial osteotomy and fixation of Tomofix (DePuy Synthes). (B) Artifical bone graft (ChronOS, DePuy Synthes). (C) Artifical bone graft (GeneX, Biocomposites Ltd.).

postoperatively, and at the final follow-up examination. A weight bearing line (WBL) percentage was calculated using standing long-cassette radiographs of the lower extremities. The WBL was determined by drawing a line from the center of the femoral head to the middle point of the proximal talar joint surface. Then, the WBL percentage was calculated as the horizontal distance from the WBL to the medial edge of the tibial plateau, divided by the width of the tibial plateau (Fig. 2A and B).

\section{Postoperative Rehabilitation}

For the first 6 postoperative weeks, patients were allowed to perform toe-touch weight bearing using 2 crutches and a brace. After removing the drains on the second postoperative day, active physical therapy with strengthening exercises and continuous passive motion was initiated. After 6 weeks, patients began full weight bearing. Return to normal sporting activities, including jogging, was permitted at 6 months postoperatively.

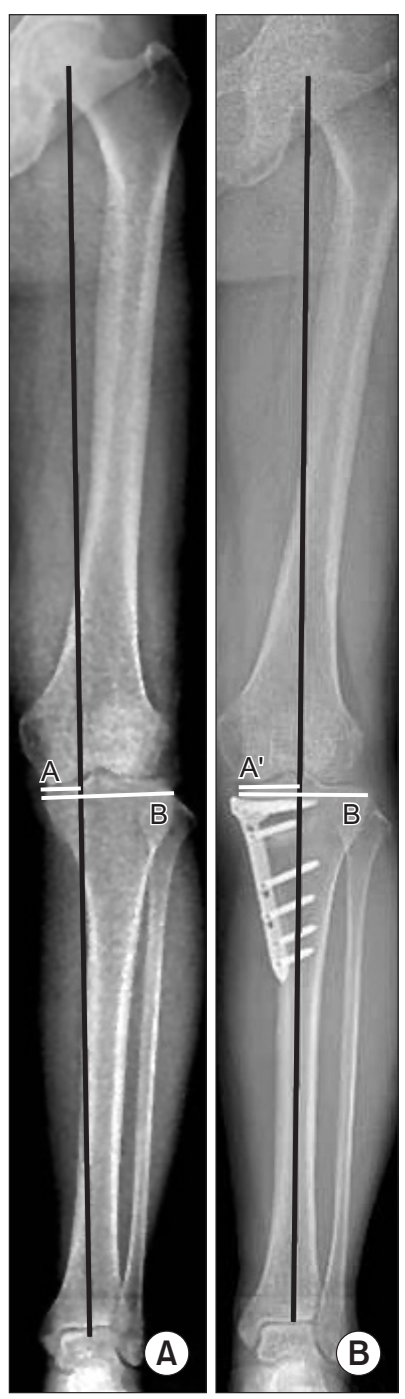

Fig. 2. Weight bearing line (WBL) extending from the center of the femoral head to the center of the ankle joint with a crossing point at the knee joint. The WBL percentage was then calculated as the horizontal distance from the WBL to the medial edge of the tibial plateau divided by the width of the tibial plateau. (A) Preoperative mechanical axis (A/ $B)$. (B) Postoperative mechanical axis $\left(\mathrm{A}^{\prime} / \mathrm{B}\right)$. The mechanical axis was shifted to a point $62 \%$ lateral on the transverse diameter of the tibial plateau. A, A': horizontal distance from the WBL to the medial edge of the tibial plateau, B: width of the tibial plateau.

\section{Second-Look Arthroscopic Findings}

Healing status of the repaired meniscus was classified according to the method of Seo et al.") (complete healing, lax healing, scar tissue healing, or failed healing). Complete healing was defined as meniscal continuity with no cleft, no lifting on probing, and normal meniscal tension at the repair site (Fig. 3). Lax healing was defined as an apparent increase in meniscus lifting and mobility on probing with good meniscal continuity. Scar tissue healing was defined as a meniscus that could be easily raised on 

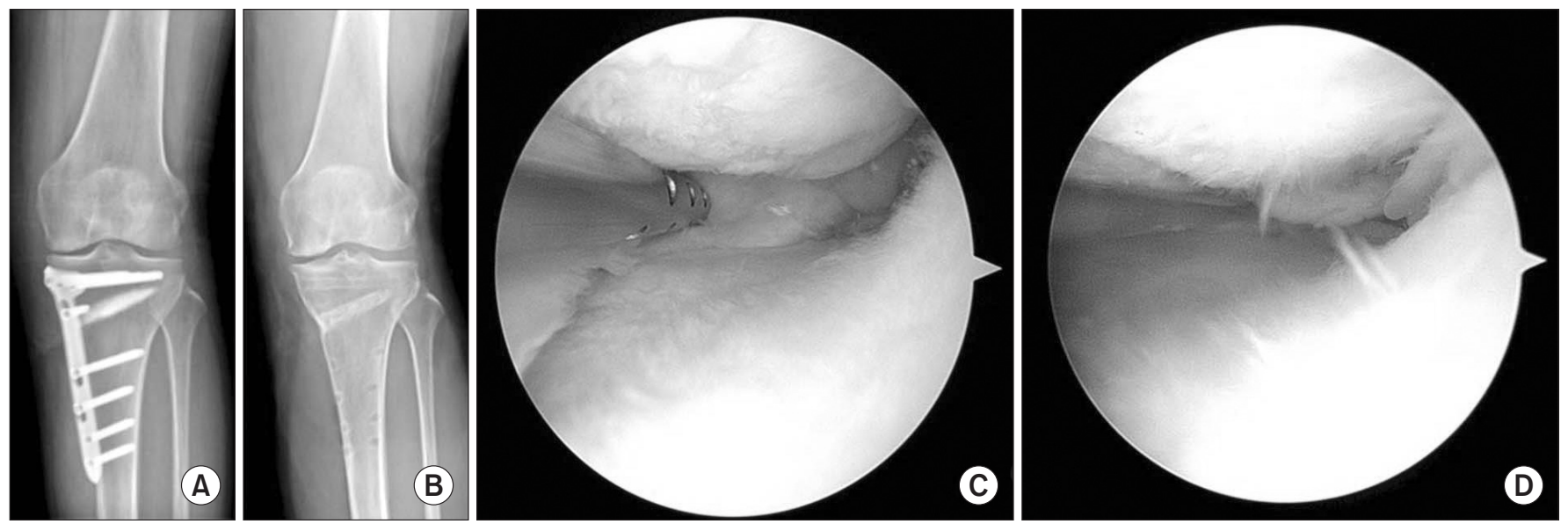

Fig. 3. (A, B) Radiographs obtained before and after metal removal. (C) Arthroscopic image showing a complete root tear of the posterior horn of the medial meniscus. (D) Second-look arthroscopy showing lax healing.
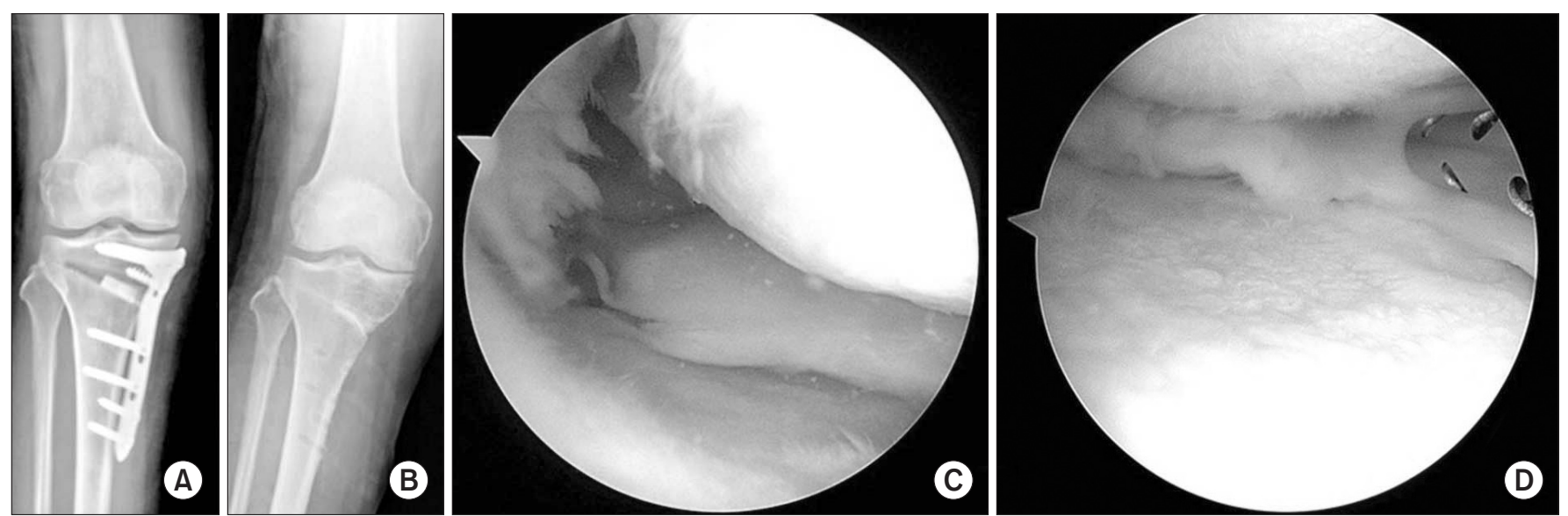

Fig. 4. (A, B) Radiographs obtained before and after metal removal. (C) Arthroscopic image showing a complete root tear of the posterior horn of the medial meniscus. (D) Second-look arthroscopy showing scar healing.
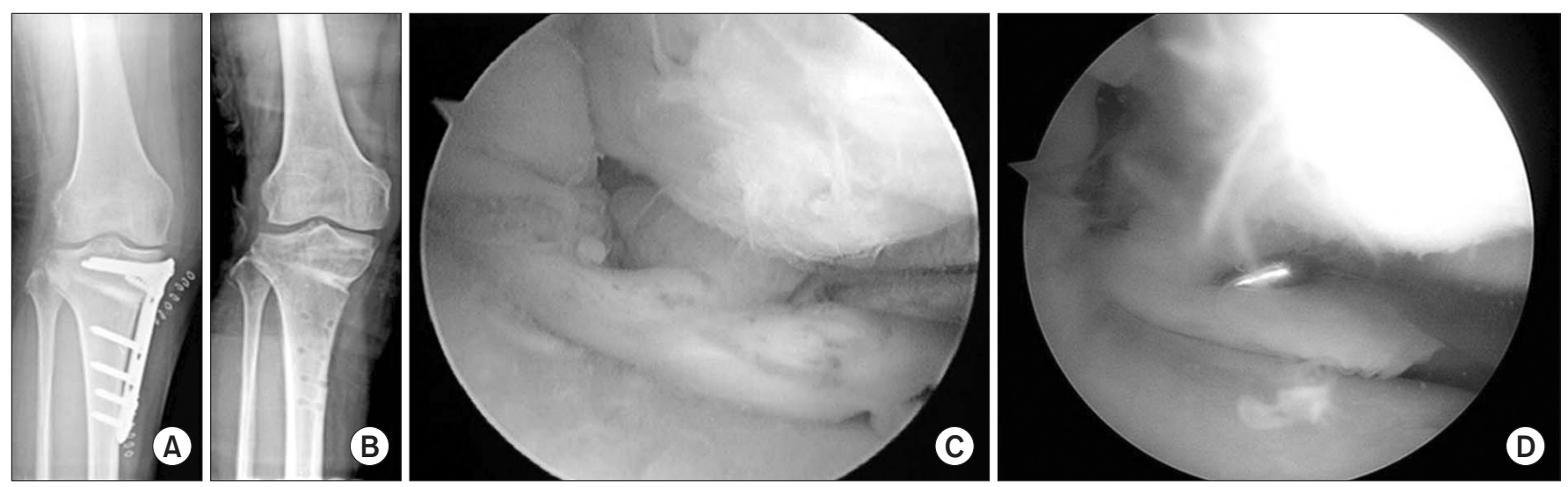

Fig. 5. (A, B) Radiographs obtained before and after metal removal. (C) Arthroscopic image showing a complete root tear of the posterior horn of the medial meniscus. (D) Second-look arthroscopy showing failed healing. 
probing and showed no true meniscal continuity, except for some connecting scar tissue fibers between the tibial attachment site and posterior horn of the medial meniscus (Fig. 4). Finally, failed healing was defined as no continuity and no evidence of meniscal healing at the repair site (Fig. 5).

The cartilage regeneration status was macroscopically evaluated to assess the extent of surface area of the former defect covered by stable regenerated cartilage, which appeared to be fibrocartilage. It was classified according to a simplified modification of the International Cartilage Research Society macroscopic cartilage evaluation as follows: grade 3, no coverage or less than $50 \%$ defect coverage (poor); grade 2, 50\% coverage or more (good); and grade 1 , complete or nearly complete coverage of the original lesion (excellent) ${ }^{18)}$.

\section{Clinical Evaluation}

The clinical evaluation was based on Lysholm knee scores and Hospital for Special Surgery (HSS) scores. These evaluations were performed before MOWHTO and again after the second-look arthroscopy.

\section{Statistical Analysis}

Statistical analysis was conducted using IBM SPSS ver. 21.0 (IBM Corp., Armonk, NY, USA). A nonparametric Wilcoxon signed-rank test and parametric c-square test were used to compare data preoperatively and postoperatively. An independentsample Kruskal-Wallis test was used to compare factors affecting PRTMM healing and cartilage regeneration. A p-value $<0.05$ was considered significant.

Table 1. Demographics and Detailed Results

\begin{tabular}{|c|c|c|c|c|c|c|c|c|}
\hline Case & Sex & $\begin{array}{l}\text { Age } \\
(\mathrm{yr})\end{array}$ & $\begin{array}{l}\text { Healing status } \\
\text { of PRTMM }\end{array}$ & $\begin{array}{l}\text { Chondral lesion } \\
\text { (modified ICRS) }\end{array}$ & $\begin{array}{l}\text { WBL } \\
(\%)\end{array}$ & $\begin{array}{c}\text { Kellgren- } \\
\text { Lawrence grade }\end{array}$ & $\begin{array}{l}\text { HSS } \\
\text { score }\end{array}$ & $\begin{array}{c}\text { Lysholm } \\
\text { score }\end{array}$ \\
\hline 1 & $\mathrm{M}$ & 53 & Lax & Good & $25 / 52$ & III/III & 82 & 80 \\
\hline 2 & $\mathrm{~F}$ & 51 & Scar & Good & $27 / 72$ & III/III & 78 & 78 \\
\hline 3 & $\mathrm{M}$ & 54 & Fail & Excellent & $34 / 56$ & III/III & 77 & 70 \\
\hline 4 & $\mathrm{~F}$ & 57 & Fail & Good & $29 / 72$ & III/II & 81 & 83 \\
\hline 5 & $\mathrm{M}$ & 54 & Scar & Poor & $30 / 55$ & III/III & 88 & 77 \\
\hline 6 & $\mathrm{~F}$ & 61 & Fail & Poor & $13 / 74$ & III/III & 85 & 77 \\
\hline 7 & $\mathrm{~F}$ & 58 & Fail & Poor & $29 / 69$ & $\mathrm{II} / \mathrm{II}$ & 90 & 86 \\
\hline 8 & $\mathrm{~F}$ & 51 & Fail & Poor & $32 / 54$ & III/II & 80 & 68 \\
\hline 9 & $\mathrm{~F}$ & 57 & Lax & Poor & $33 / 70$ & III/III & 89 & 75 \\
\hline 10 & $\mathrm{~F}$ & 59 & Fail & Poor & $30 / 75$ & II/II & 88 & 62 \\
\hline 11 & $\mathrm{~F}$ & 50 & Scar & Good & $27 / 51$ & III/II & 79 & 81 \\
\hline 12 & $\mathrm{~F}$ & 51 & Lax & Poor & $30 / 72$ & III/III & 76 & 75 \\
\hline 13 & $\mathrm{~F}$ & 56 & Lax & Good & $25 / 63$ & III/III & 75 & 82 \\
\hline 14 & $\mathrm{~F}$ & 53 & Scar & Excellent & $33 / 55$ & $\mathrm{II} / \mathrm{II}$ & 82 & 77 \\
\hline 15 & $\mathrm{~F}$ & 49 & Fail & Poor & $29 / 62$ & II/II & 81 & 79 \\
\hline 16 & $\mathrm{~F}$ & 59 & Scar & Poor & $38 / 54$ & II/II & 80 & 63 \\
\hline 17 & $\mathrm{~F}$ & 53 & Fail & Poor & $43 / 64$ & II/II & 80 & 79 \\
\hline 18 & $\mathrm{~F}$ & 60 & Fail & Poor & $11 / 72$ & III/III & 86 & 83 \\
\hline 19 & $\mathrm{~F}$ & 59 & Scar & Good & $33 / 60$ & III/III & 83 & 88 \\
\hline 20 & $\mathrm{~F}$ & 56 & Fail & Poor & $40 / 72$ & $\mathrm{II} / \mathrm{II}$ & 86 & 69 \\
\hline 21 & $\mathrm{~F}$ & 56 & Fail & Poor & $48 / 69$ & III/III & 82 & 75 \\
\hline 22 & $\mathrm{~F}$ & 53 & Fail & Poor & $4 / 52$ & III/III & 84 & 82 \\
\hline 23 & $\mathrm{~F}$ & 50 & Lax & Good & $34 / 50$ & II/II & 82 & 85 \\
\hline 24 & $\mathrm{~F}$ & 60 & Fail & Good & $23 / 59$ & II/II & 85 & 76 \\
\hline
\end{tabular}

PRTMM: posterior root tear of the medial meniscus, ICRS: International Cartilage Repair Society, WBL: weight bearing line, HSS: Hospital for Special Surgery. 
Table 2. Assessment of Factors Associated with Healing of the Posterior Root Tear of the Medial Meniscus

\begin{tabular}{lcccc}
\hline \multicolumn{1}{c}{ Variable } & $\begin{array}{c}\text { Lax } \\
\text { healing }\end{array}$ & $\begin{array}{c}\text { Scar } \\
\text { healing }\end{array}$ & $\begin{array}{c}\text { Failed } \\
\text { healing }\end{array}$ & p-value \\
\hline No. of patients & 5 & 6 & 13 & \\
Age (yr) & 53.4 & 54.3 & 55.9 & 0.35 \\
Preop WBL (\%) & 29.4 & 31.3 & 28.0 & 0.86 \\
Postop WBL (\%) & 61.4 & 57.8 & 65.3 & 0.20 \\
WBL difference & 32.0 & 26.5 & 37.8 & 0.37 \\
Preop K-L grade & 2.8 & 2.67 & 2.54 & 0.58 \\
Postop K-L grade & 2.8 & 2.54 & 2.38 & 0.30 \\
HSS at last follow-up & 80.8 & 81.6 & 83.4 & 0.45 \\
Lysholm at last follow-up & 79.4 & 77.3 & 76.1 & 0.78 \\
\hline
\end{tabular}

Preop: preoperative, WBL: weight bearing line, Postop: postoperative, K-L: Kellgren-Lawrence, HSS: Hospital for Special Surgery.

\section{Results}

Overall, the mean age at the time of operation was 56.3 years (range, 43 to 74 years). The duration of follow-up ranged from 5 to 46 months, with a mean of 19.5 months.

Of 24 patients who underwent a second-look arthroscopic examination, none had a completely healed meniscus (Table 1). The study group comprised 21 women and 3 men with a mean age of 55 years (range, 49 to 61 years). Approximately $46 \%$ of patients showed some degree of PRTMM healing without undergoing a meniscal healing procedure. Of 24 patients, 5 showed lax healing (21\%), 6 showed scar healing (25\%), and 13 showed failed healing (54\%). The healing status of PRTMM showed no relationship to sex, age, preoperative WBL, postoperative WBL, WBL difference, preoperative Kellgren-Lawrence grade, or postoperative Kellgren-Lawrence grade (Table 2).

A similar result was observed for cartilage regeneration. The progression of chondral lesions was not observed in any patient; however, some improvement was observed. Cartilage regeneration did not show a statistically significant relationship with any of the aforementioned factors (Table 3).

The mean Lysholm score increased from 34.7 (range, 31 to 43) preoperatively to 77.1 (range, 70 to 88 ) at the final follow-up examination, and the mean HSS score significantly increased from 36.5 (range, 28 to 46 ) preoperatively to 82.4 (range, 77 to 90 ) at the final follow-up examination. Clinical symptoms also significantly improved $(\mathrm{p}<0.05)$. However, the clinical scores did not correlate with the PRTMM healing status and cartilage regeneration.
Table 3. Assessment of Factors Associated with Cartilage Healing

\begin{tabular}{lcccc}
\hline \multicolumn{1}{c}{ Variable } & $\begin{array}{r}\text { Excellent } \\
\text { recovery }\end{array}$ & $\begin{array}{c}\text { Good } \\
\text { recovery }\end{array}$ & $\begin{array}{c}\text { Poor } \\
\text { recovery }\end{array}$ & p-value \\
\hline No. of patients & 2 & 8 & 14 & \\
Age (yr) & 53.5 & 54.5 & 55.5 & 0.70 \\
Preop WBL (\%) & 33.5 & 27.8 & 29.2 & 0.23 \\
Postop WBL (\%) & 55.5 & 59.8 & 65.2 & 0.24 \\
WBL difference & 22.0 & 32.0 & 36.0 & 0.37 \\
Preop K-L grade & 2.5 & 2.75 & 2.57 & 0.66 \\
Postop K-L grade & 2.5 & 2.5 & 2.64 & 0.92 \\
HSS at last follow-up & 79.5 & 80.6 & 83.9 & 0.15 \\
Lysholm at last follow-up & 73.5 & 81.6 & 75.0 & 0.08
\end{tabular}

Preop: preoperative, WBL: weight bearing line, Postop: postoperative, K-L: Kellgren-Lawrence, HSS: Hospital for Special Surgery.

\section{Discussion}

Recently, PRTMM has become increasingly recognized. There are several treatment methods for PRTMM, including conservative treatment and surgical treatment. Surgical treatment may involve partial meniscectomy or meniscal repair using various techniques. The current trend is to repair PRTMM using suture anchors and pullout sutures for suitable patients who meet indications in order to restore the main function of the meniscus. For a complete PRTMM, pullout suture repair or suture anchor repair of the meniscus may be used to restore hoop tension. However, some studies have reported that complete healing is not always observed in patients who have undergone PRTMM surgical repair, and they recommend that additional treatment modalities be instituted ${ }^{9,14)}$. In a study by Seo et al. ${ }^{9)}$, complete healing was not observed; however, $45 \%$ of patients showed lax healing, 36\% showed scar healing, and 19\% failed to heal. With respect to pullout repairs, Lee et al. ${ }^{13)}$ reported that 10 knees (47.6\%) had healed completely, and Kim et al. ${ }^{12)}$ reported that $64 \%$ of patients healed completely. Koenig et al. ${ }^{3)}$ reported that the ideal candidates for surgical repair of PRTMM were young patients with a clear trauma history and preserved chondral surface. This suggests that repair of PRTMM is a subject of debate.

With the development of HTO, including previous arthroscopic examinations, it has been recognized that medial osteoarthritis is often accompanied by PRTMM. Although HTO is most commonly used to treat unicompartmental osteoarthritis, few reports have examined the treatment options for PRTMM with varus deformities ${ }^{19,20)}$. Knee varus deformity is a condition where the mechanical axis of the lower extremity is displaced medially. Valgus-producing HTOs were designed to shift the mechanical axis 
laterally, transferring the load to the knee compartment, which is asymptomatic ${ }^{21}$. The main cause of painful sensation in patients with combined PRTMM and varus deformity is the medial shift of the mechanical axis. Thus, HTO can result in clinical improvements.

In the present study, slight healing of PRTMM was observed in some patients. Hence, decreasing axial load-bearing stress in the medial compartment, in some patients, may heal PRTMM, similar to remodeling of articular cartilage. However, complete healing was not observed. The posterior root of the medial meniscus showed an increase in meniscus lifting and mobility on probing. Thus, it was concluded that MOWHTO could not restore knee joint kinematics and function completely back to normal. However, the condition of PRTMM in patients who underwent MOWHTO did not correspond with the clinical outcomes. The Lysholm and HSS scores significantly improved, even in patients with failed PRTMM repair who underwent second-look arthroscopy. The comparison between the healed and failed groups of PRTMM showed no statistical differences.

The other findings of this study were that degenerative cartilage was partially regenerated in some patients, and postoperative limb alignment affected the clinical outcomes. Although partial regeneration of the degenerative cartilage was observed in some patients, the results were not statistically significant. In addition, no statistically significant relationship was observed between clinical outcomes and cartilage regeneration at the time of second-look arthroscopy in the current study. There has been debate about the correlation between cartilage regeneration and clinical results. Bergenudd et al. ${ }^{18)}$ reported an improvement in the cartilage in 9 knees, no change in 8 knees, and deterioration in 2 knees at a mean of 2 years after HTO. Furthermore, they suggested that no correlation was observed between cartilage improvement and clinical and radiographic outcomes. Akizuki et al. ${ }^{22)}$ reported that postoperative clinical outcomes were not related to the degree of repair of the articular surface.

Kanamiya et al. ${ }^{10)}$ showed significant differences at the time of second-look arthroscopy in the mean Japanese Orthopaedic Association score and mean mechanical axis percentage between medial compartments. In addition, the clinical results were better for the group with ideal postoperative limb alignment than for the group with a lack of correction or overcorrection.

MOWHTO is most commonly used to treat medial osteoarthritis. It continues to have a role in a relatively younger and more active subset of patients. It may be a good symptomatic treatment of varus osteoarthritis regardless of whether PRTMM or cartilage is repaired.
This study had several limitations. First, the study was a retrospective, nonrandomized, sequential review. Therefore, selection bias may have affected the results. Second, there was no control group. Other factors involving the surgeon (i.e., the surgeon's experience and surgical technique) as well as factors involving the patients (i.e., occupation and activity) may have affected the healing of PRTMM and cartilage regeneration. Third, the size of the patient cohort was relatively small (24 patients). Lastly, the follow-up period was somewhat short.

\section{Conclusions}

The healing status of the meniscus and cartilage regeneration did not correlate with the clinical outcomes in the present study. Without the meniscal treatment of medial decompression and MOWHTO, PRTMM and cartilage degeneration cannot heal enough. However, clinical symptoms could be improved by shifting the mechanical axis. Regardless of healing of PRTMM or cartilage regeneration, MOWHTO is a good treatment choice for medial osteoarthritis of the knee in select patients.

\section{Conflict of Interest}

No potential conflict of interest relevant to this article was reported.

\section{References}

1. Villegas DF, Hansen TA, Liu DF, Donahue TL. A quantitative study of the microstructure and biochemistry of the medial meniscal horn attachments. Ann Biomed Eng. 2008;36:12331.

2. Ozkoc G, Circi E, Gonc U, Irgit K, Pourbagher A, Tandogan $\mathrm{RN}$. Radial tears in the root of the posterior horn of the medial meniscus. Knee Surg Sports Traumatol Arthrosc. 2008; 16:849-54.

3. Koenig JH, Ranawat AS, Umans HR, Difelice GS. Meniscal root tears: diagnosis and treatment. Arthroscopy. 2009;25: 1025-32.

4. Allaire R, Muriuki M, Gilbertson L, Harner CD. Biomechanical consequences of a tear of the posterior root of the medial meniscus. Similar to total meniscectomy. J Bone Joint Surg Am. 2008;90:1922-31.

5. Bin SI, Kim JM, Shin SJ. Radial tears of the posterior horn of the medial meniscus. Arthroscopy. 2004;20:373-8.

6. Harner CD, Mauro CS, Lesniak BP, Romanowski JR. Biome- 
chanical consequences of a tear of the posterior root of the medial meniscus: surgical technique. J Bone Joint Surg Am. 2009;91 Suppl 2:257-70.

7. Jones AO, Houang MT, Low RS, Wood DG. Medial meniscus posterior root attachment injury and degeneration: MRI findings. Australas Radiol. 2006;50:306-13.

8. Lerer DB, Umans HR, Hu MX, Jones MH. The role of meniscal root pathology and radial meniscal tear in medial meniscal extrusion. Skeletal Radiol. 2004;33:569-74.

9. Seo HS, Lee SC, Jung KA. Second-look arthroscopic findings after repairs of posterior root tears of the medial meniscus. Am J Sports Med. 2011;39:99-107.

10. Kanamiya T, Naito M, Hara M, Yoshimura I. The influences of biomechanical factors on cartilage regeneration after high tibial osteotomy for knees with medial compartment osteoarthritis: clinical and arthroscopic observations. Arthroscopy. 2002;18:725-9.

11. Choi NH, Son KM, Victoroff BN. Arthroscopic all-inside repair for a tear of posterior root of the medial meniscus: a technical note. Knee Surg Sports Traumatol Arthrosc. 2008; 16:891-3.

12. Kim SB, Ha JK, Lee SW, Kim DW, Shim JC, Kim JG, Lee MY. Medial meniscus root tear refixation: comparison of clinical, radiologic, and arthroscopic findings with medial meniscectomy. Arthroscopy. 2011;27:346-54.

13. Lee JH, Lim YJ, Kim KB, Kim KH, Song JH. Arthroscopic pullout suture repair of posterior root tear of the medial meniscus: radiographic and clinical results with a 2 -year followup. Arthroscopy. 2009;25:951-8.

14. Nha KW, Wang KH, Shetty GM, Lee CS, Kim JI. Posterior reattachment of a radial tear in the posterior root of the medial meniscus. Orthopedics. 2011;34:276-80.

15. Park YS, Moon HK, Koh YG, Kim YC, Sim DS, Jo SB, Kwon
SK. Arthroscopic pullout repair of posterior root tear of the medial meniscus: the anterior approach using medial collateral ligament pie-crusting release. Knee Surg Sports Traumatol Arthrosc. 2011;19:1334-6.

16. Seo JH, Li G, Shetty GM, Kim JH, Bae JH, Jo ML, Kim JS, Lee SJ, Nha KW. Effect of repair of radial tears at the root of the posterior horn of the medial meniscus with the pullout suture technique: a biomechanical study using porcine knees. Arthroscopy. 2009;25:1281-7.

17. Sterett WI, Steadman JR, Huang MJ, Matheny LM, Briggs KK. Chondral resurfacing and high tibial osteotomy in the varus knee: survivorship analysis. Am J Sports Med. 2010; 38:1420-4.

18. Bergenudd H, Johnell O, Redlund-Johnell I, Lohmander LS. The articular cartilage after osteotomy for medial gonarthrosis: biopsies after 2 years in 19 cases. Acta Orthop Scand. 1992;63:413-6.

19. Nha KW, Lee YS, Hwang DH, Kwon JH, Chae DJ, Park YJ, Kim JI. Second-look arthroscopic findings after open-wedge high tibia osteotomy focusing on the posterior root tears of the medial meniscus. Arthroscopy. 2013;29:226-31.

20. Lee DW, Ha JK, Kim JG. Medial meniscus posterior root tear: a comprehensive review. Knee Surg Relat Res. 2014;26: 125-34.

21. Kfuri M, Lobenhoffer P. High tibial osteotomy for the correction of varus knee deformity. J Knee Surg. 2017;30:40920.

22. Akizuki S, Yasukawa Y, Takizawa T. Does arthroscopic abrasion arthroplasty promote cartilage regeneration in osteoarthritic knees with eburnation? A prospective study of high tibial osteotomy with abrasion arthroplasty versus high tibial osteotomy alone. Arthroscopy. 1997;13:9-17. 